\title{
PENGARUH SUHU DAN WAKTU SEDUH TERHADAP KADAR KLORIN TEH CELUP DI POLTEKKES KEMENKES BENGKULU TAHUN 2011
}

\author{
Halimah *, Leni Marlina*, Agus Widada** \\ Poltekkes Bengkulu, Jurusan Analis Kesehatan, Jl. Indragiri no.3 \\ Poltekkes Bengkulu, Jurusan Analis Kesehatan, Jl. Indragiri no.3 \\ Poltekkes Bengkulu, Jurusan Kesehatan Lingkungan, Jl. Indragiri no.3
}

\begin{abstract}
The tea bag is packed with a tea bag made of special paper and given a thread. Many Peoples are still do not know that the paper used to wrap tea contains chlorine. Chlorine is a substance used in the paper industry serves as a bleach and disinfectant. unconsciously, the longer brewing of tea cause the chlorine contained in the paper tea bags will also be dissolved. This study aims to determine the temperature and the effective time for brewing the tea bag so that the chlorine content of tea steeping water at low concentrations. This type of research is a quasi experimental laboratory. The study population was all the tea bags, measuring 2 grams. The number of samples used 27 tea bags, divided into 9 treatments and 3 replications. The results of statistical tests indicate there is a difference levels of chlorine between the temperature variation and brewed time. LSD test at 5\% there are differences in average levels of chlorine in the treatment of $\mathrm{A} 1 \mathrm{~B} 1$ and $\mathrm{A} 1 \mathrm{~B} 2$ to $\mathrm{A} 1 \mathrm{~B} 3, \mathrm{~A} 2 \mathrm{~B} 1$ and $\mathrm{A} 2 \mathrm{~B} 3$ and $\mathrm{A} 3 \mathrm{~B} 1 \mathrm{a} 2 \mathrm{~b} 2$ on and $\mathrm{A} 3 \mathrm{~B} 2$ to $\mathrm{A} 3 \mathrm{~B} 3$. Low levels of chlorine in the treatment of A1B1 Yaitu suhu $60 \mathrm{c}$ dalam waktu 3 menit (0004 ppm) and the highest levels of chlorine in the treatment of A3B3 Yaitu suhu $100 \mathrm{C}$ dalam waktu 7 menit (0013 ppm).
\end{abstract}

\begin{abstract}
Abstrak : Teh celup adalah teh yang dikemas dengan kantong terbuat dari kertas khusus dan diberi benang. Masyarakat masih banyak yang belum tahu bahwa kertas yang digunakan untuk membungkus teh mengandung klorin. Klorin yaitu zat yang digunakan di industri kertas berfungsi sebagai pemutih dan desinfektan. Tanpa disadari semakin lama menyeduh teh maka klorin yang terdapat dalam kertas kantong teh celup juga akan terlarut. Penelitian ini bertujuan untuk mengetahui suhu dan waktu efektif penyeduhan pada teh celup agar kandungan klorin air seduhan teh pada konsentrasi terendah. Jenis penelitian ini merupakan quasi eksperimental laboratorium. Populasi penelitian adalah semua teh celup yang berukuran 2 gram. Jumlah sampel yang digunakan 27 kantong teh celup yang terbagi atas 9 perlakuan dan 3 ulangan. Hasil uji statistik menunjukkan terdapat perbedaan kadar klorin antara variasi suhu dan waktu seduh yang berbeda. Pada uji LSD 5\% ada perbedaan rata-rata kadar klorin pada perlakuan A1B1 dan A1B2 terhadap A1B3, A2B1 dan A2B2 terhadap A2B3 serta A3B1 dan A3B2 terhadap A3B3. Kadar klorin terendah pada perlakuan A1B1 (0.004 ppm) dan kadar klorin tertinggi pada perlakuan A3B3 (0.013 ppm)
\end{abstract}

Kata kunci : teh celup, suhu, waktu seduh, kadar klorin

Teh merupakan salah satu hasil olahan komoditi pertanian yang dibuat dari daun pucuk tanaman Camellia sinensis. Seiring dengan perkembangan zaman serta teknologi, maka pada saat ini banyak sekali kita jumpai industri pengolahan teh dengan menghasilkan berbagai macam produk akhir seperti teh kering, teh celup dan bahkan teh dalam kemasan botol yang mana kesemuanya dapat memberikan kemudahan bagi kita untuk minum teh secara praktis (Siregar, 2009).
Semakin berkembang zaman yang semula mengkonsumsi teh bubuk yang diseduh kemudian beralih ke teh celup. Teh celup adalah teh dengan ukuran halus dan dikemas dengan kantong yang terbuat dari kertas khusus dan diberi benang yang berfungsi sebagai pegangan sewaktu teh tersebut dicelupkan dalam air panas di cangkir. Teh celup beredar di pasaran dalam berbagai merek. Dari sekian banyak merek teh yang beredar di Indonesia merek utama yang menjadi market leader untuk teh celup adalah teh dengan merek sariwangi. 
Menurut penelitian Sumarwan tentang persepsi popularitas dan kualitas terhadap merek teh celup yang dikonsumsi masyarakat maka merek teh celup yang paling popular dan paling sering diminum adalah teh sariwangi yaitu $82,8 \%$ pada persepsi kepopulerannya dan $68 \%$ responden mengkonsumsi teh sariwangi.

Sebagai salah satu minuman yang digemari juga mempunyai kelebihan yang memberikan banyak manfaat bagi kesehatan. Akan tetapi tidak semua masyarakat tahu bahwa kertas kantong yang digunakan untuk membungkus teh mengandung klorin. Klorin yaitu zat yang digunakan di industri kertas yang berfungsi sebagai pemutih dan desinfektan kertas sehingga kertas bebas dari bakteri pembusuk serta tahan lama. Menurut WHO (2004) batas ambang residu kl-orin pada air sebesar 0,5 ppm. Namun dalam ketentuan Badan Standar Nasional Indonesia (SNI) 06-4824-1998 yang mensyaratkan batas maksimum klorin pada air adalah 0,011-4,0 mg/lt.

Jika kadar klorin melebihi ambang batas yang telah ditetapkan maka akan memberikan bau dan rasa yang tidak enak pada air dan juga berakibat buruk apabila dikonsumsi. Perlu diwaspadai akumulasi kronik dalam tubuh karena klorin dapat menimbulkan efek bagi kesehatan, apalagi bila dikonsumsi secara terus menerus (Suryaningrum, 2007). Seperti yang dijelaskan dalam penelitian yang dilakukan oleh Suryana yang bertujuan untuk menentukan kadar residu klorin pada air baku dalam pembuatan minuman ringan PT. CCB Indonesia Unit Medan bahwa orang yang meminum air yang mengandung klorin memiliki kemungkinan lebih besar untuk terkena kanker kandung kemih dan usus besar. Kemudian dijelaskan juga bahwa pada hasil studi efek klorin pada binatang ditemukan kemungkinan kerusakan ginjal dan hati.

Menurut peraturan Menteri Kesehatan RI No. 772/Menkes/Per/XI/88, dalam Sinuhaji 2009, bahwa klorin tidak tercatat sebagai bahan tambahan pangan (BTP) dalam kelompok pemutih dan pematang tepung begitu juga halnya belum ada nilai standar klorin pada minuman. Serta dalam penelitian Suryaningrum (2007), diperoleh klorin tertinggi pada teh celup sebesar 0,036 ppm dan terendah $0,010 \mathrm{ppm}$, nilai ini masih rendah jika dibandingkan dengan nilai yang telah ditetapkan oleh WHO dan masih dalam nilai yang diizinkan oleh SNI.

Faktor-faktor yang mempengaruhi kecepatan penetrasi atau terlarutnya klorin pada air teh adalah suhu dan waktu rendaman (seduh). Menurut Suyitno (1989), kelarutan suatu zat dalam air dipengaruhi oleh suhu dan waktu. Selain itu juga semakin tinggi suhu akan mempercepat reaksi kimia berarti mempercepat larutnya klorin di dalam kantong teh. Konsumen biasanya mengkonsumsi teh menggunakan air panas dan waktu yang lama untuk menyeduh teh dengan alasan semakin banyak khasiat dan warna teh akan semakin merah dan kental.

Metoda yang paling sederhana untuk mengukur klorin pada air ialah menggunakan metoda Iodometri. Penelitian ini bertujuan mengetahui pengaruh suhu dan waktu seduh terhadap kadar klorin teh celup sehingga diketahui waktu dan suhu yang tepat dalam menyeduh teh celup terhadap nilai klorin yang minimal pada air seduh kemudian dibandingkan dengan persyaratan Badan Standar Nasional Indonesia.

\section{BAHAN DAN CARA KERJA}

Jenis penelitian merupakan quasi eksperimental laboratorium untuk mengetahui kadar residu klorin pada air teh sesudah di rendam dengan variasi suhu dan variasi waktu yang pemeriksaan di laboratorium secara kuantitatif. Penelitian ini menggunakan Rancangan Acak Kelompok (RAK) dengan menggunakan dua faktorial yaitu suhu dan waktu seduh. Sampel yang digunakan hanya 1 merek teh. Adapun sampel adalah teh celup yang diambil berdasarkan konsumen terbanyak, berukuran 2 gram. Sampel dibeli di pasar kota Bengkulu dengan tehnik simple random sampling. Penelitian ini dibagi menjadi 9 perlakuan dengan 3 ulangan yang masing-masingnya sampel sebanyak 27 kantong teh celup. 
Sampel teh celup ini di seduh dengan menggunakan air masak pada variasi suhu dan variasi waktu seduh. Masing-masing air seduh di ambil untuk dilakukan pemeriksaan secara kualitatif dan kuantitatif.

Data merupakan data primer yang diperoleh dari hasil pemeriksaan sampel terhadap kadar residu klorin pada air rendaman kantong teh celup dengan metoda titrasi iodometri. Sampel teh celup di timbang dan diambil yang berukuran 2 gram, kantong teh diletakkan pada masing-masing gelas minum. Aquadest dimasak pada suhu yang telah di tetapkan $\left(60^{\circ} \mathrm{C}, 80^{\circ} \mathrm{C}, 100^{\circ} \mathrm{C}\right)$ dituangkan pada gelas yang sudah ada kantong teh celup sebanyak $250 \mathrm{ml}(\mathrm{A} 1=$ $60^{\circ} \mathrm{C}, \mathrm{A} 2=80^{\circ} \mathrm{C}, \mathrm{A} 3=100^{\circ} \mathrm{C}$ ). Kemudian di rendam selama $\mathrm{B}$ waktu penyeduhan (B1 = 3menit, B2 = 5menit, B3 = 7 menit), menggunakan pengukur waktu, tepat pada waktu yang telah ditetapkan kantong teh dikeluarkan dari rendaman. Selanjutnya air seduh kantong teh celup diambil $100 \mathrm{ml}$ untuk dilakukan analisa kadar klorin secara Iodometri. Data dianalisa dengan statistic parametrik oneway ANOVA apa-bila signifikan $\mathrm{p}<0.05$ dilanjutkan dengan uji lanjut LSD.

HASIL

\section{Kadar Klorin pada Suhu Seduh}

Rata-rata kadar klorin pada air kantong teh dengan variasi suhu seduh yaitu suhu 60 ${ }^{\circ} \mathrm{C}, 80^{\circ} \mathrm{C}, 100^{\circ} \mathrm{C}$, terlihat pada gambar di bawah ini :

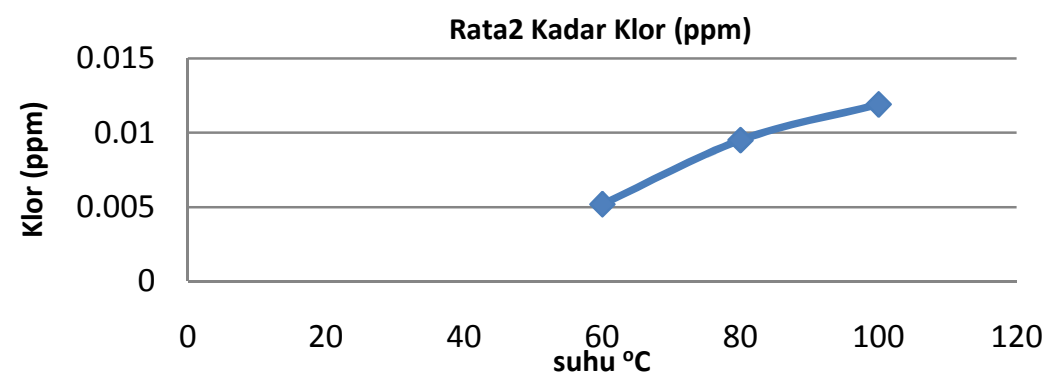

Gambar 1. Rata-rata kadar klorin kantong teh pada variasi suhu

Kadar klorin kantong teh dengan variasi waktu seduh yaitu 3 menit, 5 menit dan 7 menit dengan rata-rata kadar klorin tertinggi pada waktu 7 menit yaitu pada konsentrasi 0-.0105 ppm, terlihat pada gambar di bawah ini :

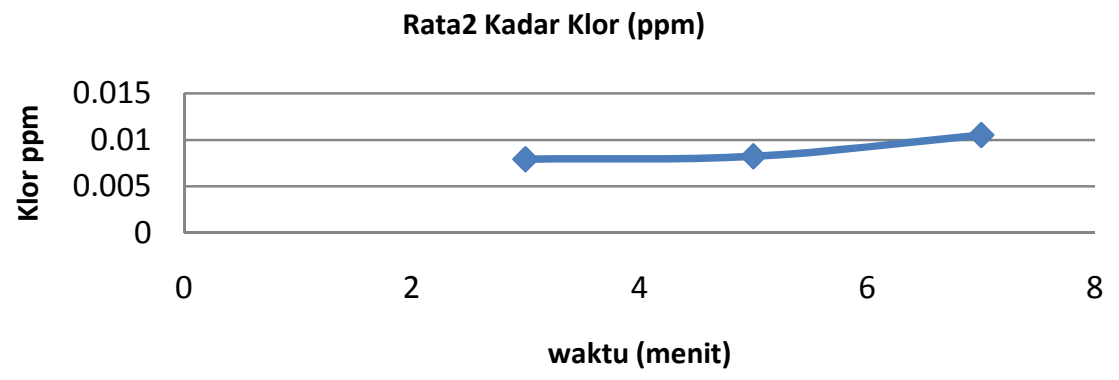

Gambar 2. Rata-rata kadar klorin kantong teh pada variasi waktu seduh

Pengaruh suhu seduh terhadap kadar klorin kantong teh dapat diketahui dengan uji one way anova. Hasil uji statistic terlihat pada tabel 1 . 
Tabel 1. Pengaruh Suhu terhadap Kadar Klorin Kantong Teh

\begin{tabular}{ccc}
\hline Suhu Seduh & Rata-rata kadar Clor (ppm) & p Value \\
\hline $60^{\circ} \mathrm{C}^{\mathrm{a}}$ & 0.0053 & \\
$80^{\circ} \mathrm{C}^{\mathrm{b}}$ & 0.0095 & 0.0005 \\
$100^{\circ} \mathrm{C}^{\mathrm{c}}$ & 0.0118 & \\
\hline
\end{tabular}

Berdasarkan uji Anova diketahui bahwa perbedaan suhu seduh sangat berpengaruh terhadap kadar klorin kantong teh. Hal ini ditunjukkan dari nilai $\mathrm{p}=$ 0,0005 pada $\alpha 0,05$, rata-rata kadar klorin tertinggi pada suhu seduh $100{ }^{\circ} \mathrm{C}$ yaitu $0,0118 \mathrm{ppm}$.
Pengaruh Waktu Seduh terhadap Kadar Klorin Kantong Teh

Pengaruh waktu seduh terhadap kadar klorin kantong teh dapat diketahui dengan uji Anova. Hasil uji statistic terlihat pada table 2.

Tabel 2. Pengaruh Waktu terhadap Kadar Klorin Kantong Teh

\begin{tabular}{lccc}
\hline Waktu Seduh & & Rata-rata kadar Clor $(\mathbf{p p m})$ & p Value \\
\hline & 3 menit & 0.0079 & 0.132 \\
& 5 menit & 0.0082 & 0.0105 \\
\hline
\end{tabular}

Berdasarkan uji statistic diketahui bahwa perbedaan waktu seduh tidak berpengaruh terhadap kadar Klorin kantong teh. Hal ini ditunjukkan dari nilai $\mathrm{p}=0.132$ pada $\alpha 0.05$, rata-rata kadar klorin tertinggi pada waktu seduh 7 menit yaitu 0.-0105 ppm.
Pengaruh Suhu dan Waktu Seduh Terhadap Kadar Klorin kantong teh.

Pengaruh suhu dan waktu seduh terhadap kadar klorin kantong teh dapat diketahui dengan uji Two Way Anova. Hasil uji statistic terlihat pada table 3 .

Tabel 3. Pengaruh Suhu dan Waktu Seduh Terhadap Kadar Klorin

\begin{tabular}{crcc}
\hline Suhu Seduh & Waktu Seduh & Kadar Clorin $(\%)$ & pValue \\
\hline \multirow{2}{*}{$60^{\circ} \mathrm{C}$} & 3 menit & $0.004 a$ & $0.004 a$ \\
& 5 menit & $0.007 b$ & 0.002 \\
\multirow{2}{*}{$80^{\circ} \mathrm{C}$} & 3 menit & $0.009 a$ & $0.009 a$ \\
\\
\multirow{2}{*}{$100{ }^{\circ} \mathrm{C}$} & 5 menit & $0.011 b$ & $0.011 a$ \\
& 7 menit & $0.011 a$ & $0.013 b$ \\
\hline
\end{tabular}

Keterangan : Huruf yang berbeda pada keterangan menunjukkan ada perbedaan nyata pada taraf 5\% menurut uji LSD (p)

Berdasarkan uji Two Way Anova diketahui bahwa suhu seduh $\left(60,80,100^{\circ} \mathrm{C}\right)$ dan waktu seduh (3, 5, 7 menit) sangat berpengaruh secara bermakna terhadap kadar klorin air teh. Hal ini ditunjukkan dengan nilai $\mathrm{p}=0.002$, sehingga uji LSD dilanjutkan. Dari tabel terlihat bahwa pada kadar klorin diberi kode dengan huruf yang berbeda. Yang mempunyai kode berbeda merupakan perbedaan yang bermakna terhadap nilai rata-rata klorin.

\section{PEMBAHASAN}

\section{Suhu Seduh}

Berdasarkan hasil analisis secara statistic, diketahui bahwa rata-rata kadar klorin tertinggi yaitu pada suhu seduh $100{ }^{\circ} \mathrm{C}$, yaitu $0.0119 \mathrm{ppm}$. Terlihat pada gambar no.1, grafik kadar klorin naik tajam dengan me-ningkatnya suhu seduh. Suhu seduh teh adalah suhu untuk melarutkan senyawasenyawa yang terkandung baik dalam teh maupun kantong teh pada air seduh, se- 
makin tinggi suhu melarutkan maka semakin banyak senyawa yang terlarut dan semakin cepat senyawa/zat tersebut melarut. Hal ini sesuai dengan teori fisika larutan bahwa kelarutan dipengaruhi oleh suhu. Terlihat dari penelitian ini bahwa kadar klorin tertinggi pada su-hu seduh $100^{\circ} \mathrm{C}$ yaitu suhu didih air. Dan sesuai dari hasil uji One Way Analisis of Variance (ANOVA) di-ketahui bahwa suhu seduh sangat berpengaruh terhadap kadar klorin kan-tong teh (pvalue 0.0005). Ada perbedaan ratarata kadar klorin yang bermakna pada ketiga variasi suhu seduh tersebut. Rata-rata kadar klorin tertinggi pada suhu seduh $100^{\circ} \mathrm{C}(0.0118 \mathrm{ppm})$. Jadi semakin tinggi su-hu air penyeduh teh celup maka akan

\section{Waktu Seduh}

Semakin banyak klorin yang terlarut pada air seduh. Suhu yang memberikan kadar klorin terendah adalah pada suhu seduh $60^{\circ} \mathrm{C}$. Berdasarkan hasil analisis se-cara statistic, diketahui bahwa kadar klorin tertinggi yaitu pada waktu seduh 7 menit, yaitu $0.0105 \mathrm{ppm}$. Semakin lama waktu seduh maka semakin tinggi kadar klorin yang terlarut pada air seduh. Namun jika dilihat pada table 2 kenaikan grafik pada ketiga waktu seduh dengan kenaikan kurva yang landai. Semakin lama waktu seduh maka semakin banyak partikel-partikel zat terlarut akan menyatu pada partikel-partikel pelarut. Dalam hal ini semakin lama waktu seduh maka klorin akan semakin banyak terlarut pada air seduh. Hal ini sesuai dengan penelitian Suryaningrum bahwa semakin lama pencelupan kadar klorin semakin tinggi, dimana waktu seduh yang menghasilkan klorin tertinggi adalah 8 menit.

Namun pada analisis bivariat antara waktu seduh dan kadar klorin dengan uji anova memberikan nilai $p$-value 0.132 , yang artinya waktu seduh tidak berpengaruh terhadap kenaikan rata-rata kadar klorin pada air seduh. Waktu seduh yang menghasilkan kadar klorin terendah adalah pada waktu 3 menit.

\section{Pengaruh Suhu dan Waktu Seduh Terhadap Kadar Klorin Kantong Teh}

Dari hasil uji two way anova, untuk melihat pengaruh suhu dan waktu seduh terhadap kadar klorin pada air seduh memberikan nilai pvalue 0.002 . ini berarti bahwa suhu dan waktu seduh sangat berpengaruh terhadap kenaikan rata-rata kadar klorin air seduh. Jadi dengan variasi waktu dan suhu seduh memberikan perbedaan nilai kadar klorin pada air seduh teh. Dari hasil penelitian ini maka diperoleh suhu dan waktu seduh yang menghasilkan kadar klorin terendah adalah suhu $60^{\circ} \mathrm{C}$ pada waktu 3 menit yaitu $0.0052 \mathrm{ppm}$. Pada suhu dan waktu seduh yang menghasilkan kadar klorin tertinggi adalah suhu $100^{\circ} \mathrm{C}$ pada waktu 7 menit yaitu $0.013 \mathrm{ppm}$. Meskipun nilai tersebut masih berada pada nilai yang telah ditetapkan SNI. Namun perlu diwaspadai klorin yang terdapat pada seduhan kantong teh celup karena jika kita rutin mengkonsumsi teh celup maka kadar klorin tersebut akan terakumulasi pada tubuh yang nantinya akan memberikan efek kesehatan.

\section{KESIMPULAN}

Berdasarkan hasil penelitian maka dapat disimpulkan bahwa terdapat hubungan yang bermakna antara suhu seduh dengan kadar klorin pada rendaman kantong teh celup. Sedangkan antara waktu seduh dengan kadar klorin pada rendaman kantong teh tidak terdapat hubungan yang bermakna. Namun berbeda dengan suhu dan waktu seduh terhadap kadar khorin pada rendaman kantong teh terdapat hubungan yang bermakna.

Disarankan kepada masyarakat pengguna teh celup sebaiknya dalam menseduh teh dengan suhu yang sekitar $60^{\circ} \mathrm{C}$ dan waktu seduh yang singkat sekitar 3 menit sehingga kadar klorin dalam teh seduh cukup rendah. Serta disarankan pada pabrik teh celup untuk mencantumkan saran penyeduhan pada suhu dan waktu seduh pada kemasan teh. 


\section{DAFTAR KEPUSTAKAAN}

Dewi. DP, 2010, Analisis Tipe Perilaku Konsumen Dalam Membeli Teh Di Pasar Tradisional Kabupaten Wonogiri, Fakultas Pertanian Universitas Sebelas Maret Surakarta., Skipsi

Handriyanto., 2010, Pendeteksian gas Klor dan Analisis Kualitatif Air PDAM Di Titik Terjauh dan Pemahaman Masyarakat Terhadap Gas Klor Di Wilayah Pelanggan IPA Jurug Kota Surakarta., Fakultas Tehnik Universitas Sebelas Maret Surakarta, Skripsi

Keenan dan Pudjaatmaka. At All, 1989, Ilmu Kimia untuk Universitas, ed keenam, Penerbit Erlangga.

Panuju. DT, , Teh dan Pengolahannya,

Sarasdewi. YP., 2010, Sikap Dan Minat Konsumen Pasar Swalayan Terhadap Produk Teh Di Surakarta., Fakultas Pertanian Universitas Sebelas Maret Surakarta., Skipsi
Sinuhaji. DN., 2009., Perbedaan Kandungan Klorin (Cl2) Pada Beras Berklorin Sebelum Dan Sesudah Dimasak Tahun 2009., Fakultas Kesehatan masyarakat Universitas Sumatra Utara., Skripsi

Sumarwan. U, 2002, Analisis hubungan antara persepsi popularitas, persepsi kualitas, persepsi harga dengan merek teh celup yang dikonsumsi, Media Gizi \& Keluarga, volume 26 (2) Desember 2002

Suryana. T, 2007, Perusahaan Global Di Indonesia Studi Kasus PT. Sosro, Tugas Leadership STMIK LIKMI BANDUNG,

Suryaningrum, 2007, Peningkatan Kadar Tanin dan Penurunan Kadar Klorin Sebagai Upaya Peningkatan Nilai Guna Teh Celup, PKM Penulisan Ilmiah, Universitas Muhammadiyah Malang 